\title{
Resposta de culturas e disponibilidade de enxofre em solos com diferentes teores de argila e matéria orgânica submetidos à adubação sulfatada
}

\author{
Tales Tiecher ( $\left.{ }^{1 *}\right)$; Danilo Rheinheimer dos Santos ('); Jimmy Walter Alvarez Rasche (1); Gustavo \\ Brunetto ( $\left.{ }^{2}\right)$; Fábio Joel Kochem Mallmann (1); Rogério Piccin (') \\ (') Universidade Federal de Santa Maria (UFSM), Departamento de Solos, 97105-900 Santa Maria (RS), Brasil. \\ (2) Universidade Federal de Santa Catarina (UFSC), Departamento de Engenharia Rural, 88034-000 Florianópolis (SC), Brasil. \\ (*) Autor correspondente: tales.t@hotmail.com
}

Recebido: 2/abr./2012; Aceito: 7/nov./2012

\section{Resumo}

Em solos com baixos teores de argila e matéria orgânica pode haver menor disponibilidade de enxofre (S) e, por esse motivo, espera-se que a adubação sulfatada incremente a produção das culturas. O trabalho objetivou avaliar a resposta de culturas e a disponibilidade de $\mathrm{S}$ em solos com diferentes teores de argila e matéria orgânica, submetidos à adubação sulfatada. $\mathrm{O}$ experimento foi realizado em vasos em casa de vegetação no período de agosto de 2004 até janeiro de 2008. Foram realizados nove cultivos sucessivos de plantas em quatro tipos de solos, submetidos à aplicação de quatro doses de S. Avaliou-se a produção de matéria seca e o acúmulo de S na parte aérea das plantas e o teor do elemento disponível no solo das camadas 0-10 e 10-20 cm. As plantas do primeiro cultivo de milho e aveia preta aumentaram a produção de matéria seca com a aplicação de S, mas o aumento da produção do milho não teve relação com os teores de S disponível da camada 0-10 cm nos solos arenosos. Mesmo com teores de S disponível nessa camada abaixo dos níveis de suficiência, não houve resposta do girassol, feijão, soja e mamona à adubação sulfatada. A quantidade de S acumulada na parte aérea das plantas e o teor de S disponível no solo aumentaram com a aplicação do nutriente. Grande parte do S migrou para a camada de 10-20 cm, especialmente nos solos arenosos e, assim, o diagnóstico da sua disponibilidade deve ser realizado nas camadas subsuperficiais do solo.

Palavras-chave: matéria seca, acúmulo de enxofre, nível de suficiência de enxofre, percolação de sulfato.

\section{Crop responses and sulfur availability in soils with different contents of clay and organic matter submitted to sulfate fertilization}

\begin{abstract}
Soils with low levels of clay and organic matter frequently had shown low sulfur (S) availability. Therefore, increases in crop yields trough sulfated fertilizations are expected. The objective of this work was to evaluate the response of crops and the $\mathbf{S}$ availability in soils with different contents of clay and organic matter submitted to sulfated fertilization. The experiment was carried out in pots in a greenhouse during the period from August 2004 to January 2008. Nine successive crops were cultivated in four classes of soils submitted to the application of four $\mathrm{S}$ levels. Dry matter yield and $\mathrm{S}$ accumulation in the shoot were evaluated. Soil samples from the soil layers of 0-10 cm and 10-20 cm were collected to quantify the available S content. Only the first cultivation of corn and black-oat increased the shoot dry matter yields due to sulfated fertilization. Besides, there was no relation between corn yield increases and the levels of available $\mathrm{S}$ from the soil layer of $0-10 \mathrm{~cm}$ in sandy soils. Even when the available $\mathrm{S}$ content in the soil layer of 0-10 cm was lower than the critical levels, no sulfate fertilization responses were observed when sunflower, bean, soybean and castor bean were cultivated. The amount of S accumulated in the shoots and the level of available S increased due to S fertilization. A large amount of sulfate also migrated to the soil layer of 10-20 cm, especially in sandy soils, and therefore, the diagnosis of $S$ availability should be made in the subsurface soil layers.
\end{abstract}

Key words: dry matter, sulfur accumulation, sulfur sufficiency level, sulfate percolation. 


\section{INTRODUÇÃO}

No solo, o enxofre (S) é encontrado predominantemente na forma orgânica. Assim, a capacidade do solo em suprir a demanda da planta pelo nutriente está estreitamente relacionada ao teor de matéria orgânica e sua mineralização, que, gradualmente, disponibilizará o $S$ na forma de sulfato para a solução do solo, o qual poderá ser absorvido pelas plantas. No entanto, a disponibilidade imediata do S é controlada pelo processo de adsorção/dessorção do sulfato, por meio do equilíbrio rápido entre aquele que está na solução e aquele da fase sólida do solo. A adsorção do sulfato depende principalmente dos teores e dos tipos de argilominerais e de óxidos presentes no solo, e os grupos funcionais das arestas quebradas da caulinita e aqueles da superfície dos óxidos de ferro são os que possuem maior capacidade de reter esse íon (Ensminger, 1954; Peak et al., 1999). $\mathrm{O}$ pH do solo, por sua vez, interfere na energia de ligação dos grupos funcionais aos cátions metálicos estruturais dos argilominerais e óxidos do solo, e seu aumento causa sua desprotonação, dificultando e até impedindo a adsorção de sulfato (Mehlich, 1964; Parfitt e Smartt, 1978; Peak et al., 1999; Casagrande et al., 2003; GoldberG, 2010). Além disso, a energia de ligação do sulfato ao solo é fraca, quando comparada, por exemplo, à do íon fosfato (JORDAN e Ensminger, 1958; Pozza et al., 2009). Esse processo potencializa sua percolaçáo no perfil do solo, especialmente em solos de textura arenosa (Osório FilHo et al., 2007).

No Estado do Rio Grande do Sul (RS) são encontrados diversos tipos de solo, decorrentes da diversidade de materiais de origem, clima, relevo, tempo de formação e organismos do solo. Além disso, o uso intensivo dos solos nos diversos sistemas de cultivo ao longo dos anos, especialmente no cultivo convencional, tem alterado suas características e propriedades. Tal fato se deve, principalmente, às grandes quantidades de solo perdidas por erosão, à drástica diminuiçâo dos teores de matéria orgânica (SolOMON et al., 2005) e à utilização de corretivos da acidez do solo, que aumentam a lixiviação do sulfato (Nodvin et al., 1986). Desse modo, espera-se que nos mais diferentes tipos de solo existam ampla variabilidade na oferta de sulfato às plantas, até porque, ainda há deposição de formas de $\mathrm{S}$ atmosférico (WANG et al., 2004; Osório Filho et al., 2007).

A Comissão de Química e Fertilidade do Solo do Rio Grande do Sul e de Santa Catarina (SC) (CQFS-RS/SC, 2004) agrupam as culturas de acordo com suas exigências em $S$, estabelecendo dois níveis de suficiência de $S$ para as plantas: de $10 \mathrm{mg} \mathrm{dm}^{-3}$ para as espécies das famílias das fabáceas, brassicáceas e liliáceas, e de $5 \mathrm{mg} \mathrm{dm}^{-3}$ para as demais. No entanto, em estudo realizado com mais de 90 mil amostras de solo das mais diversas regiōes do Rio Grande do Sul, Rheinheimer et al. (2005) relatam que $49 \%$ delas contêm teores de $S$ disponível menores do que $10 \mathrm{mg} \mathrm{dm}^{-3}$ e $12,3 \%$ possuíam teores abaixo de $5 \mathrm{mg} \mathrm{dm}^{-3}$. Assim, supóe-se que a aplicação de fertilizantes sulfatados em cultivos nos mais diversos solos do RS, especialmente naqueles com baixos teores de argila e de matéria orgânica, possa aumentar a disponibilidade de sulfato no solo e, por consequência, aumentar o rendimento das culturas.

$\mathrm{O}$ trabalho objetivou avaliar a resposta de culturas e a disponibilidade de $S$ em solos com diferentes teores de argila e matéria orgânica, submetidos à adubação sulfatada.

\section{MATERIAL E MÉTODOS}

O experimento foi desenvolvido em vasos em casa de vegetação, em Santa Maria (RS), Brasil, no período de março de 2004 a fevereiro de 2008. Cada vaso (unidade experimental) constituiu-se de uma coleta indeformada de solo. As amostras indeformadas foram coletadas em 2002, com o auxílio de um amostrador cilíndrico para tubos de PVC de $200 \mathrm{~mm}$ de diâmetro e $200 \mathrm{~mm}$ de comprimento, detalhado em Bortolon et al. (2009), que permitiu a coleta $\mathrm{de}$, aproximadamente, $11 \mathrm{~kg}$ de solo. Foram coletados quatro solos: Neossolo Quartzarênico Órtico típico (NQo), sob campo natural, no município de Manuel Viana (RS); Argissolo Vermelho Distrófico arênico (PVAd), mantido sob sistema plantio direto há 14 anos em Santa Maria (RS); Latossolo Vermelho-Amarelo Distrófico típico (LVAd), em Júlio de Castilhos (RS) e Latossolo Vermelho Distroférrico típico (LVdf), em Ibirubá (RS), ambos sob sistema plantio direto há oito anos. Para evitar as perdas de solo no decorrer do experimento, a parte inferior de cada vaso foi vedada com plástico. Em área adjacente à da coleta das amostras indeformadas de solo foram coletadas amostras deformadas na camada de $0-20 \mathrm{~cm}$, sendo os atributos químicos e o teor de argila apresentados na tabela 1 .

Antes do início do experimento, que consistiu de quinze cultivos sucessivos, foi adicionado calcário na superfície dos solos nos vasos para elevar o $\mathrm{pH}$ em água até 6,0. Além disso, foram aplicadas as doses de 0, 55, 110 e $220 \mathrm{mg}$ de $S$ vaso $^{-1}$ (Tabela 2). Estudos preliminares de curta duração e com algumas culturas indicaram que possivelmente o rendimento máximo das culturas pode ser encontrado em doses menores que $50 \mathrm{~kg}$ de $S \mathrm{ha}^{-1}$. Assim, considerando que a massa de solo em um hectare, na camada de $0-20 \mathrm{~cm}$ é de $2.400 .000 \mathrm{~kg}$, para um vaso com $11 \mathrm{~kg}$ de solo, a dose equivalente a $12 \mathrm{~kg}$ de S ha ${ }^{-1}$ é de $55 \mathrm{mg}$ de $S$ vaso $^{-1}$. Logo, nos tratamentos que receberam doses de 110 e $220 \mathrm{mg}$ de $S$ vaso $^{-1}$ acrescentou-se quantidades equivalentes a 24 e $48 \mathrm{~kg}$ de $S \mathrm{ha}^{-1}$ respectivamente. A aplicação dessas doses foi repetida antes do cultivo de gergelim (Sesamum indicum L. $-4 .^{\circ}$ cultivo), de girassol (Helianthus annus L. $-7 .^{\circ}$ cultivo) e de aveia (Avena sativa L. $-13 .^{\circ}$ cultivo). Antes do primeiro cultivo de soja (Glycine $\max$ L. $-2 .^{\circ}$ cultivo) e de trevo vesiculoso (Trifolium vesiculosum $-5 .^{\circ}$ cultivo) foram aplicadas as doses de $0 ; 18,3 ; 36,7$ e 73,3 g de $S$ vaso ${ }^{-1}$. A aplicação de $1 / 3$ das doses iniciais foi realizada no intuito de repor ao 
Tabela 1. Atributos químicos da camada de $0-20 \mathrm{~cm}$ dos solos usados no experimento

\begin{tabular}{|c|c|c|c|c|c|c|c|c|c|c|c|}
\hline \multirow{2}{*}{ Solo } & Argila(1) $^{(1)}$ & M.O. ${ }^{(2)}$ & $\mathrm{pH}-\mathrm{H}_{2} \mathrm{O}^{(2)}$ & \multirow{2}{*}{$\begin{array}{l}\text { Índice } \\
\text { SMP(2) }\end{array}$} & $\mathbf{S}^{(3)}$ & $\mathbf{P}^{(4)}$ & $\mathbf{K}^{(4)}$ & $\mathrm{Ca}^{(5)}$ & $\mathbf{M g}^{(5)}$ & $\left.A\right|^{(5)}$ & $\mathrm{CTC}_{\mathrm{pH} 7,0}{ }^{(2)}$ \\
\hline & \multicolumn{2}{|c|}{$\mathrm{g} \mathrm{dm}^{-3}$} & $(1: 1)$ & & \multicolumn{3}{|c|}{$\mathrm{mg} \mathrm{dm}^{-3}$} & \multicolumn{4}{|c|}{$\mathrm{cmol}_{\mathrm{c}} \mathrm{dm}^{-3}$} \\
\hline $\mathrm{NQo}^{(6)}$ & 80 & 6,7 & 4,7 & 6,8 & 4,8 & 8,0 & 30 & 0,5 & 0,2 & 0,20 & 2,5 \\
\hline $\operatorname{PVAd}^{(7)}$ & 140 & 29,3 & 5,3 & 5,6 & 9,3 & 18,8 & 93 & 2,7 & 0,6 & 0,15 & 10,5 \\
\hline $\operatorname{LVAd}^{(8)}$ & 320 & 27,2 & 5,1 & 5,8 & 13,6 & 9,8 & 102 & 2,4 & 0,7 & 0,65 & 8,9 \\
\hline $\operatorname{LVdf}^{(9)}$ & 640 & 32,0 & 6,6 & 6,1 & 11,4 & 4,1 & 96 & 7,5 & 2,0 & 0,00 & 13,6 \\
\hline
\end{tabular}

(1) Método da pipeta (Embrapa, 1997); () Determinado segundo Tedesco et al. (1995); ( $\left.{ }^{3}\right)$ Extraído por $\mathrm{Ca}\left(\mathrm{H}_{2} \mathrm{PO}_{4}\right)_{2}$ (Tabatabat e Bremnem, 1970); ( $\left.{ }^{4}\right)$ Extraído por Mehlich 1 (Tedesco et al., 1995); ( $\left.{ }^{5}\right)$ Extraído por KCl 1 mol L-1 (Tedesco et al., 1995); ( () Neossolo Quartzarênico Órtico típico; ( ${ }^{(7)}$ Argissolo Vermelho Distrófico arênico; ( $\left.{ }^{8}\right)$ Latossolo Vermelho-Amarelo Distrófico típico; (') Latossolo Vermelho Distroférrico típico.

Tabela 2. Manejo das culturas e quantidade de enxofre aplicada nos vasos em cada cultivo realizado em casa de vegetação

\begin{tabular}{|c|c|c|c|c|c|c|c|c|}
\hline \multirow{3}{*}{ Cultivo } & \multirow{3}{*}{ Espécie } & \multirow{2}{*}{ Colheita } & \multirow{2}{*}{$\begin{array}{l}\mathrm{N} .^{\circ} \text { de } \\
\text { plantas }\end{array}$} & \multirow{2}{*}{ Nutrientes adicionados e manejo } & \multicolumn{4}{|c|}{ Dose de enxofre } \\
\hline & & & & & 0 & 256,7 & 513,3 & 1027,7 \\
\hline & & $\mathrm{DAE}^{(2)}$ & $\begin{array}{l}\text { plantas } \\
\text { vaso- }^{-1}\end{array}$ & mg vaso-1 & \multicolumn{4}{|c|}{ mg S vaso-1 } \\
\hline $1^{(1)}$ & Canola & - & 10 & Calagem e SN (3) $+20 \mathrm{mg} \mathrm{N} \mathrm{kg}^{-1}$ solo & 0 & 55 & 110 & 220 \\
\hline $2^{(1)}$ & Soja & - & 9 & SN & 0 & 18,3 & 36,7 & 73,3 \\
\hline $3^{(1)}$ & Feijão & - & 8 & $\mathrm{SN}+2,2 \mathrm{mg}$ de $\mathrm{Mn}+30 \mathrm{mg} \mathrm{N} \mathrm{kg}^{-1}$ solo & 0 & 0 & 0 & 0 \\
\hline $4^{(1)}$ & Gergelim & - & 4 & $\mathrm{SN}+15 \mathrm{mg} \mathrm{N} \mathrm{kg}^{-1}$ solo & 0 & 55 & 110 & 220 \\
\hline $5^{(1)}$ & Trevo & - & 10 & SN & 0 & 18,3 & 36,7 & 73,3 \\
\hline $6^{(1)}$ & Trigo & - & 11 & $\mathrm{SN}+30 \mathrm{mg} \mathrm{N} \mathrm{kg}^{-1}$ solo & 0 & 0 & 0 & 0 \\
\hline 7 & Girassol & 26 & 3 & $\mathrm{SN}$ & 0 & 55 & 110 & 220 \\
\hline 8 & Sorgo & 29 & 7 & $\mathrm{SN}+20 \mathrm{mg} \mathrm{N} \mathrm{kg}^{-1}$ de solo & 0 & 0 & 0 & 0 \\
\hline 9 & Feijão & 32 & 3 & $\mathrm{SN}+16 \mathrm{mg} \mathrm{N} \mathrm{kg}^{-1}$ de solo & 0 & 0 & 0 & 0 \\
\hline 10 & Milho & 32 & 4 & $\mathrm{SN}+30 \mathrm{mg} \mathrm{N} \mathrm{kg}^{-1}$ de solo & 0 & 0 & 0 & 0 \\
\hline 11 & Soja & 28 & 3 & SN & 0 & 0 & 0 & 0 \\
\hline 12 & Mamona & 92 & 1 & Revolvimento + calagem $+33 \mathrm{mg} \mathrm{N} \mathrm{kg}^{-1}$ de solo & 0 & 0 & 0 & 0 \\
\hline 13 & Aveia & 54 & 6 & Calagem + $26 \mathrm{mg} \mathrm{N} \mathrm{kg}^{-1}$ de solo & 0 & 55 & 110 & 220 \\
\hline 14 & Milho & 53 & 7 & $26 \mathrm{mg} \mathrm{N} \mathrm{kg}^{-1}$ de solo & 0 & 0 & 0 & 0 \\
\hline 15 & Soja & 23 & 5 & SN & 0 & 0 & 0 & 0 \\
\hline
\end{tabular}

(1) Cultivo publicado por Rheinheimer et al. (2007); ( $\left.{ }^{2}\right)$ Dias após a emergência; ( $\left.{ }^{3}\right)$ Solução nutritiva de Hoagland modificada (TAIZ e ZeIGER, 2004).

solo o $S$ extraído pela parte aérea das culturas precedentes. Nos cultivos de feijão (Phaseolus vulgaris L. $-3 .^{\circ} \mathrm{e}$ 9. ${ }^{\circ}$ cultivos), de trigo (Triticum aestivum $\mathrm{L} .-6 .^{\circ}$ cultivo), de sorgo (Soghum bicolor L. $-8 .^{\circ}$ cultivo), de milho (Zea mays L. $-10 .^{\circ}$ e $14 .^{\circ}$ cultivos), de mamona (Ricinus communis L. $-12 .^{\circ}$ cultivo) e nos segundo e terceiro cultivos de soja (11. ${ }^{\circ}$ e $15 .^{\circ}$ cultivos) não foi adicionado S. Assim, ao longo do experimento, foram aplicados os totais de 0; 256,7; 513,3 e 1026,7 mg de $S$ vaso $^{-1}$. A aplicaçáo de todas as doses de $\mathrm{S}$ ao longo dos cultivos foi realizada na superfície do solo dos vasos e a fonte de $S$ usada foi $\mathrm{K}_{2} \mathrm{SO}_{4}$, utilizando $\mathrm{KCl}$ para equilibrar a quantidade de $\mathrm{K}$ aplicado em todos os tratamentos. Do $1 .^{\circ}$ ao $11 .^{\circ}$ e no 15..$^{\circ}$ cultivo também foi aplicada a solução nutritiva de Hoagland modificada (TAIZ e ZeIger, 2004). Nos cultivos da canola $\left(1 . .^{\circ}\right)$, do feijão $\left(3 .^{\circ}\right.$ e $\left.9 .^{\circ}\right)$, do gergelim $\left(4 .{ }^{\circ}\right)$, do trigo $\left(6 .^{\circ}\right)$, do sorgo $\left(8 .^{\circ}\right)$, do milho $\left(10 .^{\circ}\right.$ e $\left.14 .^{\circ}\right)$, da mamona $\left(12 .^{\circ}\right)$ e da aveia $\left(13 .^{\circ}\right)$ foi aplicado nitrogênio $(\mathrm{N})$ em cobertura nas quantidades de $20,30,16,15$, $30,20,30,26,33$ e $26 \mathrm{mg} \mathrm{kg}^{-1}$ de solo respectivamente. Antes do cultivo da mamoneira (12. ${ }^{\circ}$ cultivo) efetuou-se a homogeneização do solo, separadamente para cada uma das camadas $(0-10 \mathrm{~cm}$ e $10-20 \mathrm{~cm})$, para nova correção da acidez, aplicando-se o equivalente à metade da dose recomendada para elevar o $\mathrm{pH}$ em água do solo até 6,0. Os resultados verificados do $1 .^{\circ}$ ao $6 .^{\circ}$ cultivo foram publicados em RHeinheimer et al. (2007), e neste trabalho serão apresentados os resultados do $7 .^{\circ}$ até o $15 .^{\circ}$ cultivo. O delineamento experimental usado foi inteiramente casualizado, em esquema fatorial, sendo o fator principal os tipos de solo e o fator secundário, as doses de $S$ aplicadas, com quatro repetiçôes. Para a análise estatística dos teores de enxofre disponível do solo, considerou-se a camada do solo como o terceiro fator.

As plantas dos cultivos do girassol, sorgo, feijāo, milho, soja, mamona, aveia, milho e soja $\left(7 .^{\circ}\right.$ ao $15 .^{\circ}$ cultivos) foram colhidas, respectivamente, aos $26,29,32,32,28$, $92,54,53$, e 23 dias após a emergência (Tabela 2). A irrigaçâo em cada vaso era realizada diariamente nos meses de inverno e duas vezes ao dia no verão, mediante pesagem dos vasos para manter a capacidade de campo a $80 \%$. No momento da colheita, a parte aérea das plantas foi cortada rente à superfície do solo. Posteriormente, as amostras de tecido da parte aérea das plantas foram secas em estufa com ar forçado a $65^{\circ} \mathrm{C}$ até massa constante e, logo depois, foi determinada a produção de matéria seca. Em seguida, o 
tecido foi moído, preparado e submetido à análise do teor total de S (Tedesco et al., 1995). Também foi coletado solo nas camadas de $0-10$ e $10-20 \mathrm{~cm}$ antes dos cultivos do sorgo ( $8 .^{\circ}$ cultivo), da mamoneira ( $12 .^{\circ}$ cultivo) e do segundo e terceiro cultivos da soja (11. ${ }^{\circ}$ e $15 .^{\circ}$ cultivo). Em seguida, o solo foi seco, moído, passado em peneira de malha de 2,0 $\mathrm{mm}$ e preparado para a análise do teor de $S$ extraído por $\mathrm{Ca}\left(\mathrm{H}_{2} \mathrm{PO}_{4}\right)_{2}$, conforme método descrito por TaBatabai e Bremner (1970). Os dados de produçáo de matéria seca e de $S$ acumulado na parte aérea das plantas do $7 .^{\circ}$ e $8 .^{\circ}$ cultivos foram relacionados com os teores de $\mathrm{S}$ disponível obtidos na primeira coleta de solo, do $9 .^{\circ}$ e $10 .^{\circ}$ cultivos com os da segunda coleta de solo, do $11 .^{\circ}$ e $12 .^{\circ}$ cultivos com os da terceira coleta de solo e do $13 .^{\circ}, 14 .^{\circ}$ e $15 .^{\circ} \mathrm{cul}-$ tivos com os da quarta coleta de solo.

Os dados qualitativos foram submetidos à análise de variância e, quando os efeitos foram significativos $(\mathrm{p}<0,05)$, aplicou-se o teste de comparação de médias Tukey, tomando por base os níveis de significância de 5\% de probabilidade. Para os resultados quantitativos, foram ajustadas equaçóes de regressão quando, na análise de variância, notou-se significância no efeito dos tratamentos.

\section{RESULTADOS}

\section{Produção de matéria seca da parte aérea das plantas}

As plantas de girassol ( $7 .{ }^{\circ}$ cultivo), de sorgo ( $8 .^{\circ}$ cultivo), de feijão ( $9 .^{\circ}$ cultivo), de mamona ( $12 .^{\circ}$ cultivo), de soja (11. ${ }^{\circ}$ e $15 .^{\circ}$ cultivos) e de milho ( $14 .^{\circ}$ cultivo) não aumentaram a produção de matéria seca com a aplicação de doses crescentes de fertilizante sulfatado (Figura 1), mesmo quando os teores de $S$ disponível nos solos NQo, PVAd, LVAd e LVdf estavam abaixo dos níveis de suficiência de $10 \mathrm{mg} \mathrm{dm}^{-3} \mathrm{de} S$ para as espécies da família fabácea e de $5 \mathrm{mg} \mathrm{dm}^{-3} \mathrm{de} S$ para as demais (CQFS-RS/SC, 2004).

Apenas as plantas de milho (10. ${ }^{\circ}$ cultivo) e de aveia preta (13. ${ }^{\circ}$ cultivo) aumentaram a produção de matéria seca da parte aérea com a aplicação das doses crescentes de fertilizante sulfatado (Tabelas 3 e 4). Nesses dois cultivos, a aplicação de fertilizante sulfatado nos Latossolos (LVAd e LVdf) propiciou maiores incrementos na produçáo de matéria seca da parte aérea das plantas do que nos solos com menores teores de argila e de matéria orgânica (NQo e PVAd) (Figura 2). Nos quatro tipos de solo, o aumento na produção de matéria seca desses cultivos relacionou-se com os teores de $S$ disponível no solo da camada de $10-20 \mathrm{~cm}$ (Figura 2). Contudo, nos dois solos mais arenosos, o aumento na produção de matéria seca da parte aérea do milho (10. ${ }^{\circ}$ cultivo) náo foi relacionado com a disponibilidade de $S$ da camada de $0-10 \mathrm{~cm}$.

As produçôes de matéria seca das espécies foram diferentes entre os tipos de solos (Tabelas 3 e 4), mas tais diferenças

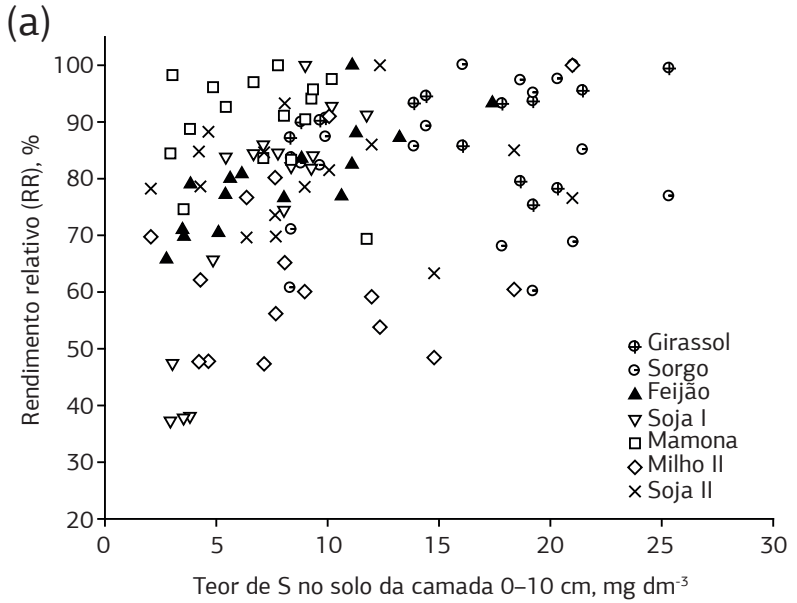

(b)

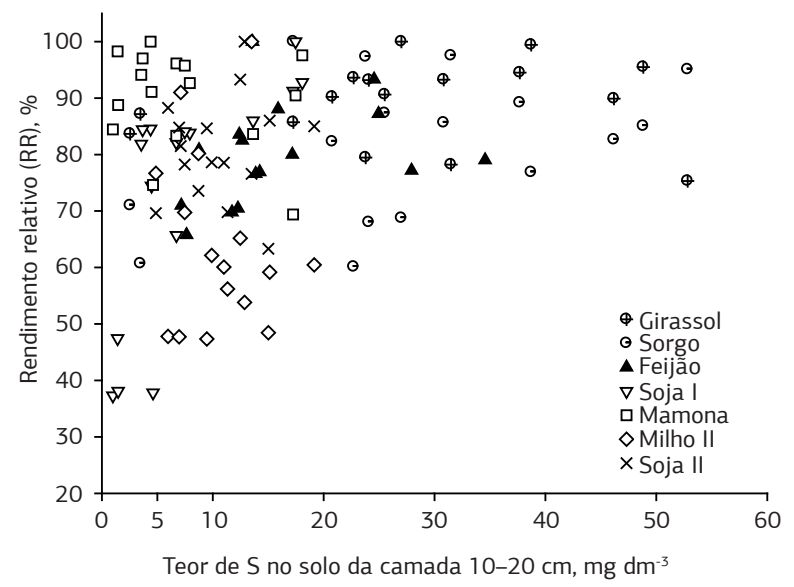

Figura 1. Relaçáo entre o teor de enxofre disponível no solo das camadas de 0-10 (a) e 10-20 cm (b) e o rendimento relativo de matéria seca da parte aérea dos cultivos que náo tiveram resposta na produção em função da aplicação de enxofre.

não tiveram relação com os teores de S-disponível no solo. As plantas de sorgo (8. ${ }^{\circ}$ cultivo), de aveia (13. ${ }^{\circ}$ cultivo) e de milho (14. ${ }^{\circ}$ cultivo), cultivadas nos quatro tipos de solo, produziram quantidades distintas de matéria seca da parte aérea mesmo com teores altos de $S$ disponível nas duas camadas de solo avaliadas $(0-10$ e $10-20 \mathrm{~cm})$. Por outro lado, as plantas de girassol ( $7 . .^{\circ}$ cultivo), de feijão ( $9 .^{\circ}$ cultivo), de mamona (12. ${ }^{\circ}$ cultivo) e de soja (11. ${ }^{\circ}$ e $15 .^{\circ}$ cultivos) tiveram produçôes semelhantes em alguns solos, mesmo quando seus teores de $S$ disponível na camada de $0-10 \mathrm{~cm}$ variaram de baixo a alto (CQFS-RS/SC, 2004).

\section{Acúmulo de enxofre na parte aérea das plantas}

A exportação de $S$ pela parte aérea das plantas aumentou com as doses de $S$ aplicadas nos quatro solos em todos os cultivos (Tabela 5). Com exceçáo dos cultivos do milho $\left(10 .^{\circ}\right) \mathrm{e}$ da aveia $\left(13 .{ }^{\circ}\right)$, o maior acúmulo de $S$ no tecido das culturas 
Tabela 3. Produção de matéria seca de culturas cultivadas em casa de vegetação em quatro tipos de solo, com diferentes teores de argila e matéria orgânica, e submetidos a três doses acumuladas de $S$

\begin{tabular}{|c|c|c|c|c|c|c|c|c|c|c|}
\hline \multirow{3}{*}{ Cultivo } & \multirow{3}{*}{ Cultura } & \multirow{3}{*}{$\begin{array}{l}\text { Tipo de } \\
\text { solo }\end{array}$} & \multicolumn{4}{|c|}{ Dose enxofre, mg S vaso-1 } & \multirow{2}{*}{\multicolumn{2}{|c|}{ Média $^{(6)}$}} & \multicolumn{2}{|c|}{ Teor S no solo } \\
\hline & & & 0 & 201,7 & 403,3 & 807,7 & & & $0-10 \mathrm{~cm}$ & $10-20 \mathrm{~cm}$ \\
\hline & & & \multicolumn{6}{|c|}{ matéria seca, g vaso-1 } & \multicolumn{2}{|c|}{$\mathrm{mg} \mathrm{dm}^{-3}$} \\
\hline \multirow{5}{*}{7} & \multirow{5}{*}{ Girassol } & $N Q o^{(1)}$ & 23,1 & 24,1 & 24,9 & 24,9 & 24,3 & c & $8,8 \mathrm{M}^{(7)}$ & $18,2 \mathrm{~A}$ \\
\hline & & PVAd $^{(2)}$ & 23,7 & 22,0 & 21,6 & 20,8 & 22,0 & b & $18,6 \mathrm{~A}$ & $31,3 \mathrm{~A}$ \\
\hline & & $\operatorname{LVAd}^{(3)}$ & 25,1 & 25,8 & 26,1 & 26,4 & 25,8 & $\mathrm{a}$ & $14,9 \mathrm{~A}$ & $35,7 \mathrm{~A}$ \\
\hline & & $\operatorname{LVdf}^{(4)}$ & 25,8 & 25,9 & 27,7 & 27,5 & 26,7 & $\mathrm{a}$ & $20,9 \mathrm{~A}$ & $28,1 \mathrm{~A}$ \\
\hline & & Média(5) & $24,4^{\text {ns }}$ & 24,4 & 25,1 & 24,9 & $C V(\%)=5,96$ & & & \\
\hline \multirow{5}{*}{8} & \multirow{5}{*}{ Sorgo } & NQo & 4,0 & 3,4 & 4,6 & 4,6 & 4,2 & bc & $8,8 \mathrm{~A}$ & $18,2 \mathrm{~A}$ \\
\hline & & PVAd & 5,6 & 5,5 & 5,5 & 5,3 & 5,5 & $\mathrm{a}$ & $18,6 \mathrm{~A}$ & $31,3 \mathrm{~A}$ \\
\hline & & LVAd & 4,9 & 4,8 & 5,0 & 4,8 & 4,9 & $a b$ & $14,9 \mathrm{~A}$ & $35,7 \mathrm{~A}$ \\
\hline & & LVdf & 3,8 & 3,4 & 3,9 & 4,3 & 3,8 & c & $20,9 \mathrm{~A}$ & $28,1 \mathrm{~A}$ \\
\hline & & Média & $4,6^{\text {ns }}$ & 4,3 & 4,7 & 4,8 & CV $(\%)=19,00$ & & & \\
\hline \multirow{5}{*}{9} & \multirow{5}{*}{ Feijão } & NQo & 5,5 & 5,1 & 5,4 & 6,1 & 5,5 & $b$ & $3,4 \mathrm{~B}$ & $15,3 \mathrm{~A}$ \\
\hline & & PVAd & 6,2 & 5,9 & 6,0 & 5,9 & 5,9 & $b$ & $5,6 \mathrm{M}$ & $16,5 \mathrm{~A}$ \\
\hline & & LVAd & 5,9 & 5,9 & 6,8 & 6,7 & 6,3 & $a b$ & $10,8 \mathrm{~A}$ & $17,2 \mathrm{~A}$ \\
\hline & & LVdf & 6,3 & 6,4 & 7,7 & 7,2 & 6,9 & $\mathrm{a}$ & $12,1 \mathrm{~A}$ & $15,8 \mathrm{~A}$ \\
\hline & & Média & $6,0^{\text {ns }}$ & 5,7 & 6,5 & 6,5 & CV $(\%)=15,70$ & & & \\
\hline \multirow{5}{*}{10} & \multirow{5}{*}{ Milho } & NQo & 7,1 & 8,2 & 9,5 & 9,3 & 8,5 & $\mathrm{a}$ & $3,4 \mathrm{M}$ & $15,3 \mathrm{~A}$ \\
\hline & & PVAd & 7,3 & 6,7 & 7,8 & 7,5 & 7,0 & $b$ & $5,6 \mathrm{~A}$ & $16,5 \mathrm{~A}$ \\
\hline & & LVAd & 4,3 & 5,1 & 6,5 & 8,9 & 6,2 & $b$ & $10,8 \mathrm{~A}$ & $17,2 \mathrm{~A}$ \\
\hline & & LVdf & 2,8 & 1,8 & 4,3 & 6,0 & 3,8 & c & $12,1 \mathrm{~A}$ & $15,8 \mathrm{~A}$ \\
\hline & & Média & $5,1^{*}$ & 5,4 & 7,0 & 8,0 & CV $(\%)=22,53$ & & & \\
\hline \multirow{5}{*}{11} & \multirow{5}{*}{ Soja } & NQo & 2,0 & 1,6 & 1,6 & 1,6 & 1,7 & b & $3,3 \mathrm{~B}$ & $2,1 \mathrm{~B}$ \\
\hline & & PVAd & 3,6 & 3,2 & 3,6 & 3,5 & 3,5 & $\mathrm{a}$ & 7,9 M & $4,0 \mathrm{M}$ \\
\hline & & LVAd & 3,6 & 3,7 & 4,3 & 4,0 & 3,9 & $\mathrm{a}$ & 7,9 M & $14,3 \mathrm{~A}$ \\
\hline & & LVdf & 2,8 & 3,5 & 3,6 & 3,9 & 3,5 & $\mathrm{a}$ & $8,6 \mathrm{M}$ & $9,5 \mathrm{M}$ \\
\hline & & Média & $3,0^{\text {ns }}$ & 3,0 & 3,3 & 3,3 & CV $(\%)=20,86$ & & & \\
\hline \multirow{5}{*}{12} & \multirow{5}{*}{ Mamoneira } & NQo & 14,4 & 12,4 & 13,0 & 11,0 & $12,7^{\mathrm{ns}}$ & & $3,3 \mathrm{~B}$ & $2,1 \mathrm{~B}$ \\
\hline & & PVAd & 14,7 & 13,4 & 14,2 & 13,8 & 14,0 & & 7,9 M & $4,0 \mathrm{M}$ \\
\hline & & LVAd & 13,6 & 12,3 & 13,3 & 14,3 & 13,4 & & $7,9 \mathrm{M}$ & $14,3 \mathrm{~A}$ \\
\hline & & LVdf & 14,1 & 12,2 & 14,1 & 10,2 & 12,6 & & $8,6 \mathrm{M}$ & $9,5 \mathrm{M}$ \\
\hline & & Média & $14,2^{\text {ns }}$ & 12,6 & 13,6 & 12,3 & CV $(\%)=15,66$ & & & \\
\hline
\end{tabular}

( $\left.{ }^{1}\right)$ Neossolo Quartzarênico Órtico típico; $\left(^{2}\right)$ Argissolo Vermelho Distrófico arênico; $\left({ }^{3}\right)$ Latossolo Vermelho-Amarelo Distrófico típico; ( $\left.{ }^{4}\right)$ Latossolo Vermelho Distroférrico típico; $\left(^{5}\right)$ Médias da produçáo de matéria seca em cada dose; $\left(^{6}\right)$ Médias da produção de matéria seca seguidas pela mesma letra minúscula na coluna (média dos solos), não

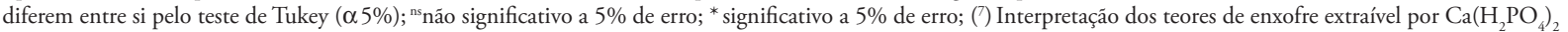

(Tedesco et al., 1995), sendo para gramíneas: $\mathrm{B}=$ baixo $\left(\leq 2,0 \mathrm{mg} \mathrm{dm}^{-3} \mathrm{de} S\right), \mathrm{M}=$ médio $\left(2,1-5,0 \mathrm{mg} \mathrm{dm}^{-3} \mathrm{de} \mathrm{S}\right), \mathrm{A}=\mathrm{alto}\left(>5,0 \mathrm{mg} \mathrm{dm}{ }^{-3} \mathrm{de} S\right)$ e para leguminosas, brássicas e

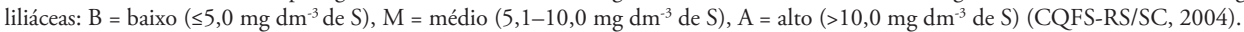

Tabela 4. Produção de matéria seca de culturas cultivadas em casa de vegetaçáo, em quatro tipos de solo, com diferentes teores de argila e matéria orgânica e submetidos a quatro doses acumuladas de $S$

\begin{tabular}{|c|c|c|c|c|c|c|c|c|c|c|}
\hline \multirow{3}{*}{ Cultivo } & \multirow{3}{*}{ Cultura } & \multirow{3}{*}{$\begin{array}{c}\text { Tipo de } \\
\text { solo }\end{array}$} & \multicolumn{4}{|c|}{ Dose enxofre, mg S vaso-1 } & \multirow{2}{*}{\multicolumn{2}{|c|}{ Média ${ }^{(6)}$}} & \multicolumn{2}{|c|}{ Teor S no solo } \\
\hline & & & 0 & 256,7 & 513,3 & 1027,7 & & & $0-10 \mathrm{~cm}$ & $10-20 \mathrm{~cm}$ \\
\hline & & & \multicolumn{6}{|c|}{ matéria seca, g vaso-1 } & \multicolumn{2}{|c|}{$\mathrm{mg} \mathrm{dm}^{-3}$} \\
\hline \multirow{5}{*}{13} & \multirow{5}{*}{ Aveia } & $\mathrm{NQo}^{(1)}$ & 2,5 & 2,8 & 3,1 & 3,3 & 2,9 & c & $6,2 A^{(7)}$ & $8,4 \mathrm{~A}$ \\
\hline & & PVAd $^{(2)}$ & 4,2 & 4,1 & 4,3 & 4,5 & 4,3 & a & $11,3 \mathrm{~A}$ & $8,6 \mathrm{~A}$ \\
\hline & & $\operatorname{LVAd}^{(3)}$ & 3,5 & 4,4 & 4,2 & 4,5 & 4,1 & $a b$ & $12,7 \mathrm{~A}$ & $14,9 \mathrm{~A}$ \\
\hline & & $\operatorname{LVdf}^{(4)}$ & 3,4 & 3,7 & 3,8 & 4,1 & 3,7 & $b$ & $7,2 \mathrm{~A}$ & $10,9 \mathrm{~A}$ \\
\hline & & Média(5) & 3,4 & 3,7 & 3,8 & 4,1 & CV ( & 64 & & \\
\hline \multirow{5}{*}{14} & \multirow{5}{*}{ Milho } & NQo & 7,9 & 7,9 & 7,9 & 10,0 & 8,4 & $\mathrm{~b}$ & $6,2 \mathrm{~A}$ & $8,4 \mathrm{~A}$ \\
\hline & & PVAd & 12,7 & 15,1 & 13,3 & 16,6 & 14,4 & $\mathrm{a}$ & $11,3 \mathrm{~A}$ & $8,6 \mathrm{~A}$ \\
\hline & & LVAd & 10,8 & 9,8 & 8,9 & 10,0 & 9,9 & $b$ & $12,7 \mathrm{~A}$ & $14,9 \mathrm{~A}$ \\
\hline & & LVdf & 11,6 & 10,3 & 9,3 & 8,0 & 9,8 & $b$ & $7,2 \mathrm{~A}$ & $10,9 \mathrm{~A}$ \\
\hline & & Média & $10,8^{\text {ns }}$ & 10,8 & 9,8 & 11,1 & CV &, 21 & & \\
\hline \multirow{5}{*}{15} & \multirow{5}{*}{ Soja } & NQo & 5,4 & 5,2 & 5,2 & 4,8 & 5,2 & $a b$ & $6,2 \mathrm{M}$ & $8,4 \mathrm{M}$ \\
\hline & & PVAd & 4,3 & 5,0 & 4,5 & 4,7 & 4,6 & $b$ & $11,3 \mathrm{~A}$ & $8,6 \mathrm{M}$ \\
\hline & & LVAd & 5,7 & 5,3 & 6,1 & 5,2 & 5,6 & $\mathrm{a}$ & $12,7 \mathrm{~A}$ & $14,9 \mathrm{~A}$ \\
\hline & & LVdf & 4,8 & 4,8 & 4,3 & 3,9 & 4,5 & $b$ & $7,2 \mathrm{M}$ & $10,9 \mathrm{~A}$ \\
\hline & & Média & $5,1^{\mathrm{ns}}$ & 5,1 & 5,0 & 4,7 & CV ( &, 32 & & \\
\hline
\end{tabular}

( $\left.{ }^{1}\right)$ Neossolo Quartzarênico Órtico típico; $\left({ }^{2}\right)$ Argissolo Vermelho Distrófico arênico; ( $\left.{ }^{3}\right)$ Latossolo Vermelho-Amarelo Distrófico típico; $\left({ }^{4}\right)$ Latossolo Vermelho Distroférrico típico; $\left(^{5}\right)$ Médias da produçáo de matéria seca em cada dose; $\left(^{(6)}\right.$ Médias da produção de matéria seca seguidas pela mesma letra minúscula na coluna (média dos solos), não diferem entre sí pelo teste de Tukey ( $\alpha$ \%\%); ns nâo significativo a $5 \%$ de erro; *significativo a $5 \%$ de erro; $(7)$ interpretaçáo dos teores de enxofre extraível por Ca( $\left.\mathrm{H}_{2} \mathrm{PO}\right)_{2}$

(Tedesco et al., 1995), sendo para gramíneas: $\mathrm{B}=$ baixo $\left(\leq 2,0 \mathrm{mg} \mathrm{dm}^{-3} \mathrm{de} S\right), \mathrm{M}=$ médio $\left(2,1-5,0 \mathrm{mg} \mathrm{dm}^{-3} \mathrm{de} \mathrm{S}\right), \mathrm{A}=\mathrm{alto}\left(>5,0 \mathrm{mg} \mathrm{dm}{ }^{-3} \mathrm{de} S\right)$, e para leguminosas, brássicas e

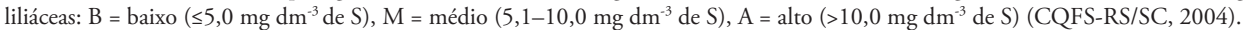



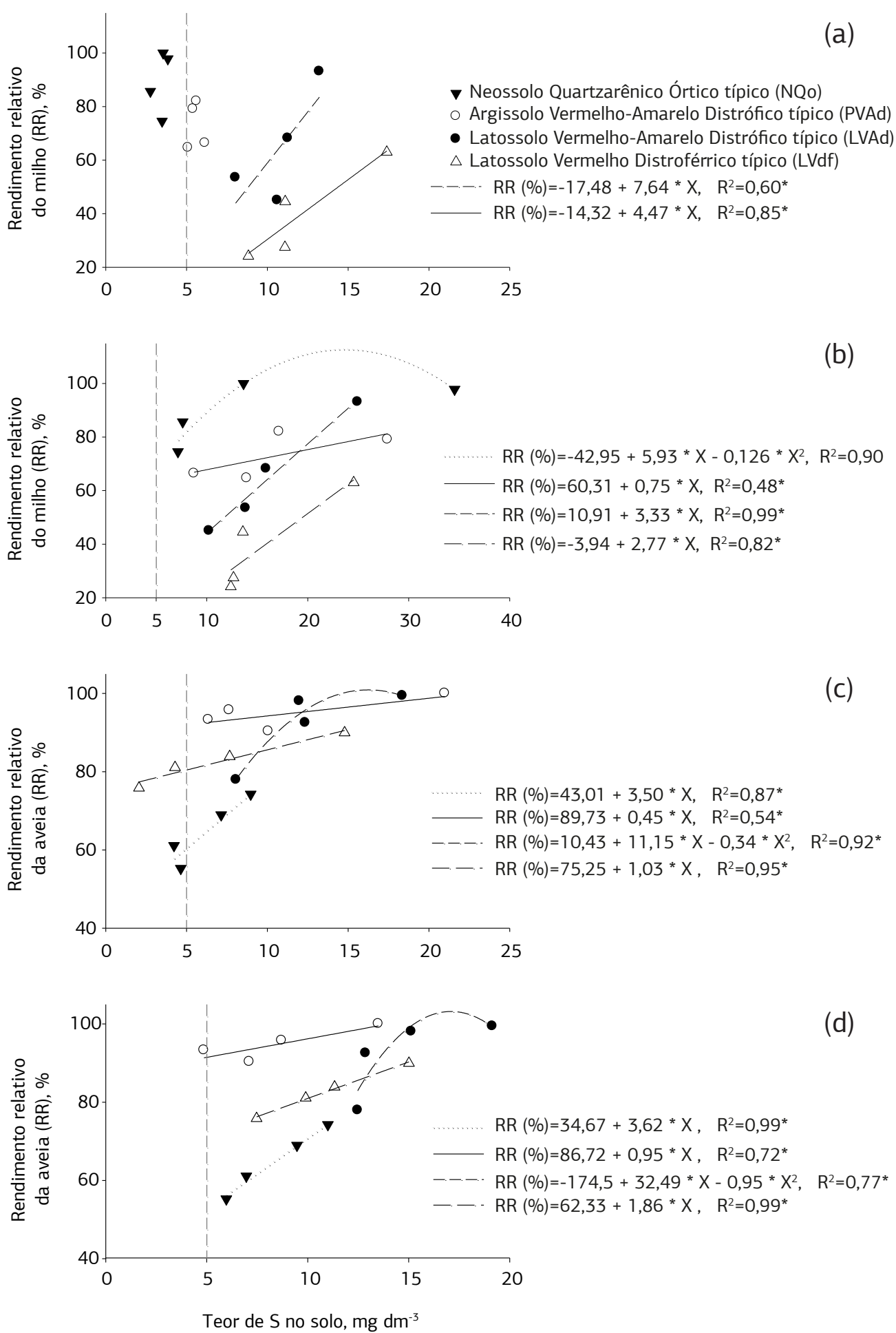

Figura 2. Relação entre o rendimento relativo de produção de matéria seca da parte aérea do primeiro cultivo de milho e da aveia e o teor de S disponível no solo nas camadas de 0-10 (a e c) e 10-20 cm (b e d), em quatro diferentes tipos de solos. X = teor de enxofre disponível do respectivo solo; *Significativo a 5\%.

não se refletiu em aumento na quantidade de matéria seca da parte aérea. Nos cultivos do girassol, do sorgo, da mamona, da aveia, e no segundo e terceiro cultivos da soja $\left(11 .^{\circ} \mathrm{e}\right.$

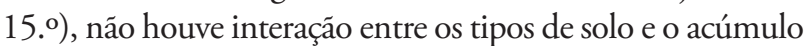
de $S$ na parte aérea das plantas. Em todos esses cultivos, tanto os teores de $S$ no solo da camada de $0-10 \mathrm{~cm}$ quanto os teores no solo da camada de $10-20 \mathrm{~cm}$ relacionaram-se com o $S$ acumulado na parte aérea das plantas.

No cultivo do feijāo $\left(9 .^{\circ}\right)$ e nos dois cultivos do milho $\left(10 .^{\circ}\right.$ e $\left.14 .^{\circ}\right)$ houve interação entre os tipos de solo e as doses 
Tabela 5. Parâmetros das regressóes ajustadas para o teor de enxofre acumulado na parte aérea das plantas submetidas à aplicação de enxofre, nos cultivos realizados em casa de vegetação

\begin{tabular}{|c|c|c|c|c|c|c|c|}
\hline \multirow{2}{*}{ Cultivo } & \multirow{2}{*}{ Cultura } & \multirow{2}{*}{ Solo } & \multirow{2}{*}{$\begin{array}{c}\text { Camada } \\
(\mathrm{cm})\end{array}$} & \multicolumn{4}{|c|}{ Parâmetro da regressão } \\
\hline & & & & $b_{0}$ & $b_{1} x$ & $b_{11} x^{2}$ & $\mathbf{R}^{2}$ \\
\hline \multirow{2}{*}{7} & \multirow{2}{*}{ Girassol } & Média $^{(1)}$ & $0-10$ & $-81,742$ & 8,7232 & - & $0,96^{*}$ \\
\hline & & Média & $10-20$ & $-48,021$ & 5,8936 & $-0,0675$ & $0,99 *$ \\
\hline \multirow{2}{*}{8} & \multirow{2}{*}{ Sorgo } & Média & $0-10$ & 1,268 & 0,4043 & - & $0,82^{*}$ \\
\hline & & Média & $10-20$ & 1,871 & 0,3395 & $-0,0041$ & $0,96^{*}$ \\
\hline \multirow{8}{*}{9} & \multirow{8}{*}{ Feijão } & $\mathrm{NQo}^{(2)}$ & $0-10$ & - & - & - & sc \\
\hline & & NQo & $10-20$ & $-10,550$ & 3,2490 & $-0,0660$ & $1,00^{*}$ \\
\hline & & PVAd $^{(3)}$ & $0-10$ & - & - & - & ns \\
\hline & & PVAd & $10-20$ & - & - & - & ns \\
\hline & & $\operatorname{LVAd}^{(4)}$ & $0-10$ & $-9,251$ & 1,6360 & - & $0,85^{*}$ \\
\hline & & LVAd & $10-20$ & $-3,178$ & 0,6711 & - & $0,85^{*}$ \\
\hline & & LVdf(5) & $0-10$ & - & - & - & SC \\
\hline & & LVdf & $10-20$ & $-117,407$ & 14,9380 & $-0,3930$ & $0,75^{*}$ \\
\hline \multirow{8}{*}{10} & \multirow{8}{*}{ Milho I } & NQo & $0-10$ & - & - & - & sc \\
\hline & & NQo & $10-20$ & 6,199 & 3,1690 & $-0,0600$ & $0,98^{*}$ \\
\hline & & PVAd & $0-10$ & - & - & - & sc \\
\hline & & PVAd & $10-20$ & $-16,340$ & 3,9780 & $-0,1020$ & $0,85^{*}$ \\
\hline & & LVAd & $0-10$ & $-13,223$ & 2,4081 & - & $0,74^{*}$ \\
\hline & & LVAd & $10-20$ & $-5,217$ & 1,0370 & - & $0,83^{*}$ \\
\hline & & LVdf & $0-10$ & - & - & - & sc \\
\hline & & LVdf & $10-20$ & $-179,506$ & 21,6410 & $-0,5547$ & $0,96^{*}$ \\
\hline \multirow{2}{*}{11} & \multirow{2}{*}{ Soja I } & Média & $0-10$ & 1,185 & 0,6811 & - & $0,97^{*}$ \\
\hline & & Média & $10-20$ & 0,069 & 1,1672 & $-0,0478$ & $1,00^{*}$ \\
\hline \multirow{2}{*}{12} & \multirow{2}{*}{ Mamona } & Média & $0-10$ & $-0,775$ & 7,4027 & - & $0,80^{*}$ \\
\hline & & Média & $10-20$ & $-44,662$ & 20,3553 & $-0,9263$ & $0,82^{*}$ \\
\hline \multirow{2}{*}{13} & \multirow{2}{*}{ Aveia } & Média & $0-10$ & 1,449 & 0,4510 & $-0,0162$ & $0,99^{*}$ \\
\hline & & Média & $10-20$ & $-0,594$ & 0,6990 & $-0,0238$ & $1,00^{*}$ \\
\hline \multirow{8}{*}{14} & \multirow{8}{*}{ Milho II } & NQo & $0-10$ & $-3,009$ & 2,6985 & - & $0,83^{*}$ \\
\hline & & NQo & $10-20$ & $-6,172$ & 3,3423 & $-0,0997$ & $0,78^{*}$ \\
\hline & & PVAd & $0-10$ & $-9,692$ & 2,8192 & - & $0,97^{*}$ \\
\hline & & PVAd & $10-20$ & $-7,779$ & 4,4357 & $-0,1760$ & $0,96^{*}$ \\
\hline & & LVAd & $0-10$ & - & - & - & ns \\
\hline & & LVAd & $10-20$ & - & - & - & ns \\
\hline & & LVdf & $0-10$ & - & - & - & ns \\
\hline & & LVdf & $10-20$ & - & - & - & ns \\
\hline \multirow{2}{*}{15} & \multirow{2}{*}{ Soja II } & Média & $0-10$ & $-0,228$ & 0,6408 & $-0,0211$ & $0,93^{*}$ \\
\hline & & Média & $10-20$ & $-2,956$ & 0,9347 & $-0,0284$ & $0,94^{*}$ \\
\hline
\end{tabular}

( $\left.{ }^{1}\right)$ Média de dezesseis repetiçốes (quatro repetiçốes das quatro doses de cada solo); ( $\left.{ }^{2}\right)$ Neossolo Quartzarênico Órtico típico; $\left({ }^{3}\right)$ Argissolo Vermelho Distrófico arênico; $\left({ }^{4}\right)$ Latossolo Vermelho-Amarelo Distrófico típico; $\left({ }^{4}\right)$ Latossolo Vermelho Distroférrico típico; ${ }^{*}$ significativo a $5 \%$ de erro; ns: năo significativo; sc: significativo a $5 \%$ de erro mas sem relaçấo com o teor de enxofre disponível no solo.

de $S$ aplicadas sobre a quantidade do nutriente acumulada na parte aérea das plantas (Tabela 5). Nesses três cultivos, o acúmulo de $S$ na parte aérea das plantas não foi significativo no cultivo do feijão sob o solo PVAd e no segundo cultivo de milho (14. ${ }^{\circ}$ cultivo) sob os solos LVAd e LVdf. Nos demais solos do $9 .^{\circ}, 10 .^{\circ}$ e $14 .^{\circ}$ cultivos, houve melhor relaçấo entre a quantidade de $S$ acumulado na parte aérea das plantas e os teores de $S$ disponível no solo da camada de 10-20 cm; nos solos LVdf e NQo quando cultivados com o feijão e nos solos LVdf, PVAd e NQo quando cultivados com o milho (10. ${ }^{\circ}$ cultivo), o acúmulo de $S$ na parte aérea das plantas não propiciou nenhuma relação com os teores de $S$ disponível da camada de 0-10 cm (Tabela 5).

\section{Teor de enxofre disponível no solo}

Os teores de $S$ disponível no solo da camada de $10-20 \mathrm{~cm}$ aumentaram com a aplicação das doses de $S$ em todos os solos, sendo esse aumento mais pronunciado nos solos NQo e PVAd do que nos Latossolos (Tabela 6). Contudo, no NQo e no PVAd, o teor de $S$ disponível no solo da camada de $0-10 \mathrm{~cm}$ nas coletas de solo realizadas antes do $8 .^{\circ}$, do $11 .^{\circ}$ e do $12 .^{\circ}$ cultivos foi igual, independentemente da dose de $S$ aplicada, enquanto na última coleta, o teor de $S$ disponível no solo dessa camada aumentou com o incremento da dose de $S$ aplicada. 
Tabela 6. Teores de enxofre disponíveis no solo das camadas $0-10$ e 10-20 cm em quatro coletas nos diferentes solos submetidos à aplicação de enxofre

\begin{tabular}{|c|c|c|c|c|c|c|c|c|}
\hline \multirow{3}{*}{ Cultivo } & \multirow{3}{*}{$\begin{array}{l}\text { Tipo de } \\
\text { solo }\end{array}$} & \multirow{2}{*}{ Camada } & \multicolumn{4}{|c|}{ Dose de enxofre, mg S vaso-1 } & \multirow{3}{*}{$\begin{array}{l}\text { Equações de } \\
\text { regressão }\end{array}$} & \multirow{3}{*}{$\mathbf{R}^{2}$} \\
\hline & & & 0 & 257 & 513 & 1027 & & \\
\hline & & $\mathrm{cm}$ & \multicolumn{4}{|c|}{$\mathrm{mg} \mathrm{S} \mathrm{dm}^{-3}$} & & \\
\hline \multirow{9}{*}{$\begin{array}{l}\text { Antes do sorgo } \\
\text { (8. }{ }^{\circ} \text { cultivo) }\end{array}$} & \multirow{2}{*}{$\mathrm{Nqo}^{(1)}$} & $0-10$ & 8,4 & 9,7 & 9,7 & 8,8 & $y=8,8$ & ns \\
\hline & & $10-20$ & 2,5 & 4,6 & 25,7 & 46,2 & $y=7,43+0,058 x$ & $0,95^{*}$ \\
\hline & \multirow{2}{*}{$\operatorname{PVAd}^{(2)}$} & $0-10$ & 18,6 & 18,7 & 20,3 & 18,6 & $y=18,6$ & ns \\
\hline & & $10-20$ & 17,3 & 23,8 & 31,5 & 48,9 & $y=16,39+0,039 x$ & $0,99^{*}$ \\
\hline & \multirow{2}{*}{$\operatorname{LVAd}^{(3)}$} & $0-10$ & 9,9 & 13,9 & 14,4 & 21,5 & $y=10,10+0,013 x$ & $0,96^{*}$ \\
\hline & & $10-20$ & 25,5 & 30,8 & 37,7 & 48,8 & $y=25,41+0,029 x$ & $0,99^{*}$ \\
\hline & \multirow{3}{*}{$\operatorname{LVdf}(4)$} & $0-10$ & 17,9 & 16,3 & 21,0 & 25,3 & $y=16,38+0,010 x$ & $0,85^{*}$ \\
\hline & & $10-20$ & 24,1 & 22,7 & 27,0 & 38,7 & $y=21,19+0,019 x$ & $0,86^{*}$ \\
\hline & & $\mathrm{DMS}^{(5)}$ solo & 8,7 & camad & & & $C V=2$ & \\
\hline \multirow{9}{*}{$\begin{array}{l}\text { Antes da soja II } \\
\left(11 .^{\circ} \text { cultivo) }\right.\end{array}$} & \multirow{2}{*}{ NQo } & 0-10 & 3,5 & 2,8 & 3,6 & 3,8 & $y=3,8$ & ns \\
\hline & & $10-20$ & 7,2 & 7,6 & 11,7 & 34,6 & $y=2,78+0,035 x$ & $0,87^{*}$ \\
\hline & \multirow{2}{*}{ PVAd } & $0-10$ & 6,1 & 5,1 & 5,6 & 5,4 & $y=5,4$ & ns \\
\hline & & $10-20$ & 8,8 & 12,3 & 17,2 & 27,9 & $y=8,06+0,024 x$ & $0,99^{*}$ \\
\hline & \multirow{2}{*}{ LVAd } & $0-10$ & 10,6 & 8,0 & 11,3 & 13,2 & $y=9,18+0,004 x$ & $0,52^{*}$ \\
\hline & & $10-20$ & 14,2 & 13,9 & 15,9 & 25,0 & $y=12,26+0,014 x$ & $0,86^{*}$ \\
\hline & \multirow{3}{*}{ LVdf } & $0-10$ & 11,1 & 8,8 & 11,1 & 17,4 & $y=8,92+0,009 x$ & $0,71^{*}$ \\
\hline & & $10-20$ & 12,7 & 12,4 & 13,6 & 24,5 & $y=10,40+0,015 x$ & $0,82^{*}$ \\
\hline & & DMS solo $=$ & $0 ; \quad[$ & amada & & & $C V=3$ & \\
\hline \multirow{9}{*}{$\begin{array}{l}\text { Antes da } \\
\text { mamona } \\
\text { (12. }{ }^{\circ} \text { cultivo) }\end{array}$} & \multirow{2}{*}{ NQo } & $0-10$ & 3,0 & 2,9 & 3,8 & 3,5 & $y=3,3$ & ns \\
\hline & & $10-20$ & 1,4 & 1,0 & 1,5 & 4,6 & $y=2,1$ & ns \\
\hline & \multirow{2}{*}{ PVAd } & $0-10$ & 7,8 & 8,0 & 6,7 & 9,3 & $y=7,9$ & ns \\
\hline & & $10-20$ & 4,4 & 4,5 & 3,7 & 3,6 & $y=4,0$ & ns \\
\hline & \multirow{2}{*}{ LVAd } & $0-10$ & 5,4 & 7,1 & 9,0 & 10,2 & $y=5,86+0,005 x$ & $0,93^{*}$ \\
\hline & & $10-20$ & 7,9 & 13,6 & 17,5 & 18,1 & $y=10,09+0,011 x$ & $0,77^{*}$ \\
\hline & \multirow{3}{*}{ LVdf } & $0-10$ & 4,9 & 8,4 & 8,9 & 11,7 & $y=5,68+0,007 x$ & $0,92^{*}$ \\
\hline & & $10-20$ & 6,7 & 6,7 & 7,5 & 17,2 & $y=4,77+0,013 x$ & $0,82^{*}$ \\
\hline & & DMS solo $=$ & 3 & amada & & & $C V=2$ & \\
\hline \multirow{9}{*}{$\begin{array}{l}\text { Antes da soja III } \\
\text { (15. }{ }^{\circ} \text { cultivo) }\end{array}$} & \multirow{2}{*}{ NQo } & $0-10$ & 4,6 & 4,2 & 7,1 & 9,0 & $y=4,06+0,004 x$ & $0,88^{*}$ \\
\hline & & $10-20$ & 6,0 & 7,0 & 9,5 & 11,0 & $y=6,10+0,005 x$ & $0,94^{*}$ \\
\hline & \multirow{2}{*}{ PVAd } & $0-10$ & 6,4 & 10,1 & 7,6 & 21,0 & $y=5,20+0,013 x$ & $0,79^{*}$ \\
\hline & & $10-20$ & 4,9 & 7,1 & 8,7 & 13,5 & $y=4,82+0,008 x$ & $0,99^{*}$ \\
\hline & & $0-10$ & 8,1 & 12,0 & 12,3 & 18,4 & $y=8,44+0,009 x$ & $0,95^{*}$ \\
\hline & LVAd & $10-20$ & 12,5 & 15,1 & 12,9 & 19,1 & $y=12,30+0,005 x$ & $0,70^{*}$ \\
\hline & & $0-10$ & 2,1 & 4,3 & 7,7 & 14,8 & $y=1,56+0,012 x$ & $0,99^{*}$ \\
\hline & LVdf & $10-20$ & 7,5 & 9,9 & 11,3 & 15,0 & $y=7,72+0,007 x$ & $0,99^{*}$ \\
\hline & & DMS solo & & amada & & & $C V=3$ & \\
\hline
\end{tabular}

$\left({ }^{1}\right)$ Neossolo Quartzarênico Órtico típico; $\left({ }^{2}\right)$ Argissolo Vermelho Distrófico arênico; $\left({ }^{3}\right)$ Latossolo Vermelho-Amarelo Distrófico típico; $\left({ }^{4}\right)$ Latossolo Vermelho Distroférrico típico; $\left({ }^{5}\right)$ Diferença mínima significativa; ns: nấo significativo a $5 \%$ de erro; ${ }^{*}$ significativo a $5 \%$ de erro.

\section{DISCUSSÃO}

Nos Latossolos submetidos à aplicação de $S$, o aumento dos teores de $S$ disponível na camada de $0-10 \mathrm{~cm}$ ocorre porque possuem maior teor de argila e, consequentemente, maior capacidade de retenção de sulfato comparativamente aos solos NQo e PVAd, que têm textura arenosa (Tabela 6) (Hug, 1997; Nodvin et al., 1986; Prietzel et al., 2008). Além disso, esses solos possuem alto teor de fósforo e elevados valores de $\mathrm{pH}$ em água, o que lhes conferem menor capacidade de adsorção de sulfato, o que potencializa a percolação do sulfato para camadas mais profundas do solo, como a camada de $10-20 \mathrm{~cm}$. Essa pode ser uma das explicaçóes para a não alteraçáo dos teores de $S$ disponível na camada de $0-10 \mathrm{~cm}$ dos solos NQo e PVAd, nas três primeiras coletas de solo. No entanto, na quarta coleta de solo (após o $14 .^{\circ}$ cultivo), que ocorreu logo após a aplicação de $S$, foi detectado aumento nos teores de $S$ disponível na camada de $0-10 \mathrm{~cm}$ dos solos PVAd e NQo. Provavelmente, esse fato ocorreu porque não houve tempo suficiente para que toda a quantidade de $S$ aplicado sobre o solo fosse percolada para as camadas abaixo de $10 \mathrm{~cm}$. Tais resultados concordam com os obtidos por Nogueira e Melo (2003), quando verificaram que a aplicaçáo de fertilizantes sulfatados em solos com textura arenosa causou aumento apenas temporário nos seus teores de $S$ disponível; de um ano para o outro náo foi observado efeito residual do fertilizante, evidenciando a alta mobilidade desse ín no perfil do solo.

O sulfato é facilmente percolado no perfil do solo porque é retido no solo por meio do mecanismo de adsorção por coordenação. Esta ocorre principalmente pela troca de ligante com a molécula de água coordenada pelos grupos funcionais oriundos das ligaçôes insatisfeitas dos cátions metálicos 
estruturais $\left(\equiv \mathrm{M}^{+0,5}\right)$ presentes nas bordas dos argilominerais e nos óxidos de ferro e alumínio do solo (Yu, 1997). Tal condiçâo existe principalmente em solos com valores de $\mathrm{pH}$ em água baixos, onde essa molécula de água coordenada $\left(\equiv \mathrm{M}^{\top} \mathrm{OH}_{2}{ }^{+0,5}\right)$ é muito instável, razão pela qual a energia de ligaçẫo do sulfato nesse sítio é menor do que, por exemplo, quando ocorre a troca com uma hidroxila. Além disso, outros ânions como o fosfato, por causa do seu menor tamanho e distribuiçâao das cargas nos seus oxigênios, conseguem se aproximar mais da superfície da partícula, sendo adsorvido preferencialmente ao sulfato.

Os teores de $S$ disponível no solo da camada de $0-10 \mathrm{~cm}$ não foram indicativos de resposta das culturas, o que pode ser atribuído em parte à alta percolação do íon sulfato para as camadas inferiores nos solos, especialmente naqueles de textura mais arenosa (Figura 1). Esse exemplo pode ser observado no primeiro cultivo de milho ( $10 .^{\circ}$ cultivo), realizado três cultivos após a aplicação de $S$ (efetuada antes do cultivo do girassol $-7 .{ }^{\circ}$ cultivo), onde grande parte do $S$ aplicado nos solos arenosos percolou e acumulou-se na camada de 10-20 cm; o fundo dos vasos foi fechado, para evitar a perda de solo, e assim, o aumento da produção de matéria seca não se relacionou com os teores de $S$ disponível no solo da camada de $0-10 \mathrm{~cm}$. Já nos Latossolos, o sulfato foi retido em maior quantidade no solo da camada de $0-10 \mathrm{~cm}$ e, por esse motivo, os teores de $S$ disponível relacionaram-se com a produçáo de matéria seca da parte aérea do milho $\left(10 .^{\circ}\right.$ cultivo). Contudo, no cultivo da aveia, como a aplicaçáo de $S$ havia sido realizada antes do plantio, a quantidade de sulfato percolada para a camada abaixo de $10 \mathrm{~cm}$ foi menor, e por isso, o incremento na produção de matéria seca da parte aérea teve boa relação com o teor de $S$ disponível no solo da camada 0-10 cm. Assim, o diagnóstico correto da disponibilidade desse nutriente em solos arenosos é possível somente se a amostragem do solo da camada superficial for realizada logo após a aplicação de $S$. Porém, isso náo implica, necessariamente, que em solos com textura arenosa e com baixos teores de matéria orgânica a adubação sulfatada proporcionará maior aumento na produção das plantas do que nos solos de textura argilosa e com maior teor de matéria orgânica (Figura 2).

O acúmulo de $S$ na parte aérea das plantas cultivadas em solos submetidos à aplicação de fertilizante sulfatado sem que haja aumento na produção de matéria seca caracteriza o "consumo de luxo" (MARSCHNER, 1995), cuja planta absorve e acumula em seus tecidos quantidades do nutriente maiores que sua necessidade. Esses resultados concordam com os obtidos por RHEINHEIMER et al. (2007), que verificaram incremento nos teores de $S$ no tecido da parte área da canola (Brassica napus L. var. napus), da soja, do feijão, do trevo vesiculoso (Trifolium vesiculosum $\mathrm{cv}$. Yuchi) e do trigo (Triticum aestivum L.), cultivados em solos submetidos a doses crescentes de S. O acúmulo de $S$ no tecido das plantas pode ser benéfico em solos com baixa capacidade de adsorver o sulfato, como aqueles de textura arenosa, porque diminui a quantidade do nutriente na solução e a probabilidade de perdê-lo por lixiviação.
A falta de relação entre os teores de $S$ disponível no solo da camada de $0-10 \mathrm{~cm}$ e a quantidade de $S$ acumulado na parte aérea das plantas reforça a idéia de que o teor desse nutriente nessa camada náo é indicativo adequado para estimar a resposta das culturas e não representa a real disponibilidade de $S$ às plantas (Tabela 5). Contudo, a relaçáo entre os teores de $S$ disponível na camada de $10-20 \mathrm{~cm}$ e o $S$ acumulado na parte aérea das plantas em todos os cultivos mostra que os teores do nutriente em camadas subsuperficiais podem predizer melhor sua real disponibilidade às plantas, além de ser mais eficaz em armazenar informaçôes sobre o histórico de adubação sulfatada nos solos. No entanto, convém relatar que o $S$ pode ter sido acumulado na camada de $10-20 \mathrm{~cm}$, porque o fundo dos vasos foi vedado para evitar as perdas de solo e, dessa forma, favorecido essa relação dos teores de $S$ disponível nessa camada com o $S$ acumulado no tecido da parte aérea das plantas, especialmente quando cultivadas em solos de textura arenosa. Para solos com textura arenosa, a avaliação dos teores de $S$ disponível no solo das camadas subsuperficiais, juntamente com a avaliação do seu teor no solo da camada superficial logo após a aplicação de enxofre, pode estabelecer com maior precisão o diagnóstico da real disponibilidade do nutriente para as plantas.

Por fim, os níveis de suficiência de $S$ no solo da camada de 0-10 cm, estabelecidos pela CQFS-RS/SC (2004), podem ser insuficientes para fins de predição da disponibilidade de $S$ e da resposta das plantas à adição desse nutriente. Além disso, o teor de suficiência de $S$, que varia em funçáo da espécie cultivada, deve considerar também o tipo de solo, pois teores semelhantes de $S$ disponível em solos diferentes podem proporcionar produções de matéria seca distintas da parte aérea; plantas cultivadas em solos diferentes, mesmo com teores diversos de $S$ disponível, podem ter produçōes similares (Tabelas 3 e 4). Outra questão a ser observada é que na adubação inorgânica de $S$ náo se deve aplicar altas doses com a finalidade de elevar o teor do nutriente no solo ao longo dos anos, principalmente em solos com baixo teor de argila, $\mathrm{pH}$ em água próximo à neutralidade e alto teor de fósforo. Também, ao se cultivar espécies com alta exigência em $S$, a aplicação do nutriente deve ser realizada concomitantemente à semeadura da cultura, com o intuito de manter a disponibilidade elevada de $S$ no solo na zona de absorção das raízes pelo maior tempo possível durante o crescimento e o desenvolvimento das plantas.

\section{CONCLUSÃO}

Apenas as plantas do primeiro cultivo de milho e da aveia preta aumentam a produção de matéria seca da parte aérea com a aplicação de enxofre no solo, mas o incremento na produção do milho não temelação com os teores desse nutriente disponível na camada de $0-10 \mathrm{~cm}$ nos solos arenosos.

Mesmo com teores de enxofre disponível no solo da camada de $0-10 \mathrm{~cm}$ abaixo dos níveis de suficiência, não há resposta das plantas do girassol, do feijão, da soja e da mamona à adubaçẫo sulfatada, constatando-se que as faixas de interpretação 
estabelecidas pela Comissão de Química e Fertilidade do Solo (RS/SC) para o teor de enxofre disponível no solo nem sempre possuem relação com a produçâo das plantas.

A quantidade de enxofre acumulada na parte aérea das plantas e o respectivo teor disponível no solo aumentam com a aplicaçáo do elemento ao solo e grande parte migra para a camada de 10-20 cm, principalmente nos solos arenosos.

$\mathrm{O}$ teor de enxofre da camada superficial do solo náo representa sua real disponibilidade e para diagnosticar sua disponibilidade, as camadas subsuperficiais do solo $(10-20 \mathrm{~cm})$ devem ser consideradas para análise.

\section{REFERÊNCIAS}

BORTOLON, L.; GIANELlO, C.; CONTE, O.; OLIVEIRA, E.S.; LEVIEN, R. Equipamento para coleta de amostras indeformadas de solo para estudos em condiçóes controladas. Revista Brasileira de Ciência do Solo, v.33, p.1929-1934, 2009.

CASAGRANDE, J.C.; ALLEONI, L.R.F; CAMARGO, O.A.; BORGES, M. Adsorção de fosfato e sulfato em solos com cargas elétricas variáveis. Revista Brasileira de Ciência do Solo, v.27, p.5157, 2003.

COMISSÃO DE QUÍMICA E FERTILIDADE DO SOLO CQFSRS/SC. Manual de adubação e calagem para os Estados do Rio Grande do Sul e Santa Catarina. 10.ed. Porto Alegre: Sociedade Brasileira de Ciência do Solo - Núcleo Regional Sul, 2004. 400p.

EMBRAPA. Manual de métodos de análise de solo. 2.ed. rev., atual. Rio de Janeiro, 1997. 212p.

ENSMINGER, L.E. Some factors affecting the absorption of sulfate by Alabama. Soil Science Society American Proceeding, v.18, p.259-264, 1954.

GOLDBERG, S. Competitive Adsorption of Molybdenum in the Presence of Phosphorus or Sulfur on Gibbsite. Soil Science, v.175, p.105-110, 2010.

HUG, S.J. In Situ Fourier Transform Infrared Measurements of Sulfate Adsorption on Hematite in Aqueous Solutions. Journal of Colloid and Interface Science, v.188, p. 415-422, 1997.

JORDAN, H.V.; ENSMINGER, L.E. The role of sulphur in soil fertility. Advances in Agronomy, v.10, p.407-434, 1958.

MARSCHNER, H. Mineral nutrition of higher plants. New York: Academic Press, 1995. 889p.

MEHLICH, A. Influence of sorbed hydroxyl and sulfate on liming efficiency, $\mathrm{pH}$ and conductivity. Soil Science Society American Proceeding, v.28, p.496-499, 1964.

NODVIN, S.C.; DRISCOLL, C.T.; LIKENS, G.E. The effect of $\mathrm{pH}$ on sulfate adsorption by a forest soil. Soil Science, v.142, p.6975, 1986.

NOGUEIRA, M.A.; MELO, W.J. Enxofre disponível para a soja e atividade de arilsulfatase em solo tratado com gesso agrícola. Revista Brasileira de Ciência do Solo, v.27, p.655-663, 2003.
OSÓRIO FILHO, B.D.; RHEINHEIMER, D.S.; SILVA, L.S.; KAMINSKI, J.; DIAS, G.F. Deposição do enxofre atmosférico no solo pelas precipitaçôes pluviais e respostas de culturas à adubação sulfatada em sistema plantio direto. Ciência Rural, v.37, p.712719, 2007.

PARFITT, R.L.; SMART, R.S.C. The mechanism of sulfate absorption of iron oxides. Soil Science Society of America Journal, v.42, p.48-50, 1978.

PEAK, D.; FORD, R.G.; SPARKS, D.L. An in Situ ATR-FTIR Investigation of Sulfate Bonding Mechanisms on Goethite. Journal of Colloid and Interface Science, v.218, p.289-299, 1999.

POZZA, A.A.A.; CURI, N.; GUILHERME, L.R.G.; MARQUES, J.J.G.S.M.; ENIO T. S.; COSTA, E.T.S.; ZULIANI, D.Q.; MOTTA, P.E.F.; MARTINS, R.S.; OLIVEIRA, L.C.A. Adsorção e dessorção aniônicas individuais por gibbsita pedogenética. Química Nova, v.32, p. 99-105, 2009.

PRIETZEL, J.; THIEME, J.; HERRE, A.; SALOM, M.; EICHERT, D. Differentiation between adsorbed and precipitated sulphate in soils and at microsites of soil aggregates by sulphur K-edge XANES. European Journal of Soil Science, v.5, p.730-743, 2008.

RHEINHEIMER, D.S.; RASCHE, J.W.A.; OSÓRIO FILHO, B.D.; SILVA, L.S.; BORTOLUZZI, E.C. Resposta de culturas à aplicação de enxofre e a teores de sulfato num solo de textura arenosa sob plantio direto. Ciência Rural, v.35, p. 562-569, 2005 .

RHEINHEIMER, D.S.; RASCHE, J.W.A.; OSÓRIO FILHO, B.D.; SILVA, L.S. Resposta à aplicação e recuperação de enxofre em cultivos de casa de vegetação em solos com diferentes teores de argila e matéria orgânica. Ciência Rural, v.37, p.363-371, 2007

SOLOMON, D.; LEHMANN, J.; LOBE, I.; MARTINEZ, C.E.; TVEITNES, S.; DU PREEZ, C.C.; AMELUNG, W. Sulphur speciation and biogeochemical cycling in long-term arable cropping of subtropical soils: evidence from wet-chemical reduction and SKedge XANES spectroscopy. European Journal of Soil Science, v.56, p.621-634, 2005.

TABATABAI, M.A; BREMNER, J.M. An alkaline oxidation method for determination of total sulphur in soils. Soil Science Society American Proceeding, v.34, p.62-65, 1970.

TAIZ, L.; ZEIGER, E. Fisiologia vegetal. 3.ed. Porto Alegre: Artmed, 2004. 719p.

TEDESCO, M.J.; VOLKWEISS, S.J.; BOHNEN, H.; GIANELLO, C.; BISSANI, C.A. Análise de solo, plantas e outros materiais. Porto Alegre: Universidade Federal do Rio Grande do Sul, 1995. 215p. (Boletim Técnico de Solos, 5)

WANG, T.J.; HU, Z.Y.; XIE, M.; ZHANG, Y.; XU, C.K.; CHAO, Z.H. Atmospheric sulfur deposition onto different ecosystems over China. Environmental Geochemistry and Health, v.26, p.169177, 2004.

YU, T.R. Chemistry of variable charge soils. 1.ed. New York: Oxford University Press, 1997. 505p. 